Artikel Penelitian

\title{
Kandungan Kadmium pada Lipstik Warna Coklat Gelap yang Terdaftar dan Tidak Terdaftar di BPOM yang Dijual di Pasar Raya Kota Padang
}

Titi Isnaini ${ }^{1}$, Elmatris $^{2}$, Roza Silvia ${ }^{3}$

\begin{abstract}
Abstrak
Kadmium merupakan salah satu zat berbahaya yang terdapat dalam lipstik yang berefek pada organ-organ tubuh manusia. Penelitian ini bertujuan untuk mengetahui uji kualitatif dan kuantitatif kandungan kadmium pada lipstik yang dijual di Pasar Raya Kota Padang. Penelitian ini merupakan penelitian deskriptif dengan sampel lipstik berwarna coklat gelap sebanyak 15 lipstik yang terdaftar dan 13 lipstik tidak terdaftar di Badan Pengawasan Obat dan Makanan (BPOM). Pemeriksaan kandungan kadmium dilakukan di Laboratorium Teknik Lingkungan Universitas Andalas dari April-Mei 2018. Instrument yang digunakan adalah Spektrofotometri Serapan Atom. Hasil penelitian menunjukkan bahwa 15 lipstik yang terdaftar dan 13 lipstik yang tidak terdaftar di Badan Pengawasan Obat dan Makana (BPOM) didapatkan semua sampel mengandung cadmium namun masih memenuhi syarat yang telah ditetapkan Badan Pengawasan Obat dan Makana (BPOM) 2011. Didapatkan nilai rata-rata kandungan kadmium pada lipstik yang terdaftar 0,8396 ppm dan pada lipstik yang tidak terdaftar 1,2174. Kesimpulan penelitian ini bahwa seluruh sampel mengandung kadmium namun masih memenuhi syarat yang telah ditetapkan Badan Pengawasan Obat dan Makana (BPOM) 2011 yaitu < 3 ppm. Bagi masyarakat agar lebih hati-hati lagi dalam memilih kosmetik.
\end{abstract}

Kata kunci: lipstik, kadmium, spektrofotometri serapan atom

\section{Abstract}

Cadmium is one of hazard subtances contained in lipstick effect in the organs of the human body. This study aims to know the qualitative a quantitative test the content of cadmium in lipstick in hypermarket in Padang City. The type of research is descriptive with fifteen dark brown lipsticks sample that registered, and thirteen lipsticks are not registered in National Agency of Drug and Food Control (BPOM). The research held a at Environmental Engineering Laboratory of Universitas Andalas in April 2018 until May in 2018. The instrument used is Spectrophotometry Atomic Absorption. The result showed those fifteen lipsticks that registered, and thirteen lipsticks not registered in BPOM all samples contain cadmium, but still qualify. The requirement by National Agency of Drug and Food Control (BPOM) 2011. The average value of the content of cadmium lipstick that registered is 0,8396 ppm and lipstick not registered are 1,2174. The conclusion is all samples are positive contain cadmium but still quality the requirement by National Agency of Drug and Food Control (BPOM) 2011. All samples contain cadmium quality the requirement by National Agency of Drug and Food Control (BPOM) that is less than 3 ppm. For the public to be more careful in choosing cosmetics.

Keywords: Lipstick, cadmium, spectrophotometry atomic absorption

Affiliasi penulis: Pendidikan Dokter FK Unand (Fakultas Kedokteran Universitas Andalas Padang); 2. Bagian Kimia FK Unand; 3 Bagian Histologi FK Unand

Korespondensi : Titi Isnaini, Email: titiisnaini.ti@gmail.com Telp: 085263391187

\section{PENDAHULUAN}

Menurut teori Johm Gordon sehat pada dasarnya yakni gambaran keadaan seimbang dari berbagai faktor. Penyakit timbul bila terjadi gangguan dari keseimbangan tersebut yang disebabkan oleh adanya perubahan dari satu faktor atau lebih. Penyakit 
itu ditentukan oleh tiga faktor yaitu penyebab penyakit, pejamu dan lingkungan. Salah satu yang termasuk dalam lingkungan ini yaitu kosmetik. ${ }^{1}$

Kosmetik berasal dari kata yunani yaitu kosmetikos yang berarti keterampilan menghias dan mengatur. $^{2}$ Salah satu kosmetik yang sering digunakan oleh wanita adalah lipstik. $^{3}$ Lipstik merupakan campuran dari lilin, minyak dan pewarna dari berbagai konsentrasi untuk menghasilkan suatu produk akhir. ${ }^{4}$ Lipstik digunakan untuk mewarnai bibir sehingga dapat meningkatkan estetika dalam tata rias wajah. ${ }^{5}$ Lipstik juga digunakan untuk melembabkan bibir yang dapat kering akibat cuaca panas maupun dingin. Lipstik harus aman dan tidak mengandung bahan-bahan berbahaya karena dapat tertelan bersama makanan dan minuman yang dikonsumsi, sehingga departemen kesehatan RI mengatur larangan terhadap bahan-bahan tertentu agar lipstik yang beredar aman untuk digunakan. ${ }^{6}$

Salah satu zat pencemar yang dapat mengkontaminasi lispstik adalah logam berat. Logam berat yang dapat berasal dari bahan baku atau berasal dari lingkungan yang dapat masuk selama proses produksi. Logam berat ini sangat berbahaya bagi kesehatan tubuh manusia, karena sifat-sifat yang dimilikinya. Pada dasarnya logam berat merupakan komponen alami yang terdapat di kulit bumi yang tidak bisa didegradasi ataupun dihancurkan. ${ }^{7}$ Logam berat memiliki sifat dapat terakumulasi pada jaringan tubuh apabila melebihi batas toleransi akan mengakibatkan keracunan bagi manusia. ${ }^{8}$ Contoh logam berat yang sering sebagai pencemar yaitu Timbal $(\mathrm{Pb})$, Kadmium (Cd), Merkuri (Hg), Arsenik (As). ${ }^{7}$

Beberapa faktor yang diduga dapat menyebabkan pencemaran kadmium dan timbal pada lipstik adalah bahan dasar yang digunakan secara alami mengandung $\mathrm{Pb}$ seperti pada beewax yang mengandung $\mathrm{Pb} \leq 10 \mathrm{ppm}$. Pewarna yang digunakan mengandung kadmium dan timbal seperti iron oxide yang mengandung kadmium $<1 \mathrm{ppm}$ dan timbal $<10$ ppm. ${ }^{8}$ Selain itu cemaran kadmium dan timbal dapat ditemukan pada saat produksi seperti berasal dari baterai dan timbal pada peralatan untuk produksi lipstik yang menggunakan cat mengandung kadmium dan timbal. ${ }^{9}$

\section{Berdasarkan hasil pengawasan Badan} Pengawasan Obat dan Makanan (BPOM) di seluruh Indonesia pada awal tahun 2012 sampai bulan oktober 2012 ditemukan 48 kosmetik yang mengandung zat kimia yang berbahaya dan dilarang. ${ }^{10}$ Badan Pengawas Obat dan Makanan (BPOM) mengeluarkan peringatan publik yang bertujuan agar masyarakat tidak menggunakan kosmetik tersebut karena dapat membahayakan kesehatan. ${ }^{10}$ Menurut peraturan BPOM RI tahun 2011 bahwa kadmium merupakan bahan yang dilarang dalam kosmetik dan belum adanya ketetapan batas aman cemaran logam berat kadmium, sehingga untuk batas aman cemaran logam berat kadmium pada penelitian ini mengacu pada ketetapan dari Departemen Kesehatan Kanada yaitu 3 ppm. ${ }^{11}$

Penelitian di beberapa negara pada Mei 2013 dijumpai adanya kadmium didalam lipstiknnya. ${ }^{12}$ Kandungan kadmium yang terdapat dalam lipstik dapat terjadi secara sengaja maupun tidak sengaja. Penambahan secara sengaja bisa terjadi karena dapat membuat warna lipstik menjadi lebih menarik. Berdasarkan pada penelitian dikatakan bahwa kadar kadmium tertinggi pertama terdapat pada lipstik warna coklat gelap yaitu +4 ppm, sedangkan kadar kadmium tertinggi kedua terdapat pada lipstik warna merah muda yaitu $+3,7$ ppm. ${ }^{13}$

Berdasarkan uraian di atas, peneliti tertarik untuk mengetahui kandungan logam berat kadmium dalam lipstik berwarna coklat gelap yang beredar di Pasar Raya kota Padang. Berhubung karena penelitian kandungan kadmium pada lipstik warna merah muda sudah dilakukan oleh peneliti lain, maka disini peneliti tertarik untuk meneliti kandungan kadmium pada lipstik warna coklat gelap. Sasaran dari penelitian ini untuk melihat perbedaan kandungan kadmium pada lipstik berwarna coklat gelap yang terdaftar dan tidak terdaftar di Pasar Raya Kota Padang.

\section{METODE}

Jenis penelitian ini adalah deskriptif yaitu untuk mengetahui kandungan kadmium pada lipstik warna coklat gelap yang terdaftar dan tidak terdaftar di BPOM yang dijual di Pasar Raya kota Padang. Populasi pada penelitian ini adalah semua lipstik coklat gelap yang terdaftar dan tidak terdaftar dengan 
berbagai macam merk yang dijual di Pasar Raya Kota Padang, dengan sampel sebanyak 28 lipstik coklat gelap. Pengambilan sampel dilakukan secara total sampling.

Kandungan logam Cd pada pada lipstik diukur dengan Spektrofotometri Serapan Atom (SSA) pada proses penyerapan energi radiasi atom. Hasil yang akan diperoleh, yaitu apakah kadar kandungan kadmium memenuhi batas maksimum logam kadmium pada kosmetika sesuai dengan Peraturan Badan Pengawas Obat dan Makanan Republik Indonesia 2011.

Hasil pengukuran kandungan $\mathrm{Cd}$ akan dibandingkan dengan Peraturan Badan Pengawas Obat dan Makanan Nomor HK. 03.1.23.08.11.07517 tahun 2011 tentang Persyaratan Cemaran Mikroba dan Logam Berat dalam Kosmetik yaitu cemaran Cd tidak lebih dari $3 \mathrm{mg} / \mathrm{kg}$ atau $3 \mathrm{mg} / \mathrm{L}$ (3 ppm). ${ }^{11}$

\section{HASIL}

Penelitian telah dilakukan di laboratorium teknik lingkungan Universitas Andalas dengan jumlah sampel 28 lipstik yang dibeli di Pasar Raya kota Padang. Kandungan kadmium pada sampel lipstik dilakukan analisis kuantitatif menggunakan spektofotometri serapan atom sesuai prosedur yang telah ditetapkan Badan Standar Nasional.

Hasil Penelitian mendapatkan bahwa semua sampel lipstik yang diteliti setelah melakukan uji SSA didapatkan semua lipstik mengandung logam berat $\mathrm{Cd}$ dengan kadar yang berbeda. Kadar Cd yang tertinggi terdapat pada sampel dengan kode TT7, dan yang terendah terdapat pada sampel dengan kode T2.

Tabel 1 menunjukkan bahwa seluruh sampel masih memenuhi syarat untuk digunakan karena kandungan timbal di dalam sampel masih berada di bawah ambang batas yang ditetapkan oleh BPOM RI Nomor HK.03.1.23.07.11.6662 tahun 2011 tentang persyaratan cemaran mikroba dan logam berat dalam kosmetik yakni 20 ppm.
Tabel 1. Distribusi frekuensi keamanan kandungan $\mathrm{Cd}$ pada lipstik warna coklat gelap yang terdaftar dan tidak terdaftar di BPOM dengan yang ditetapkan BPOM R

\begin{tabular}{lcc}
\hline \multirow{1}{*}{ Kelompok } & \multicolumn{2}{c}{ Kandungan Cd } \\
\cline { 2 - 3 } & $\begin{array}{c}\text { Aman } \\
(\leq 3 p p m)\end{array}$ & $\begin{array}{c}\text { Tidak aman } \\
(\geq 3 p p m)\end{array}$ \\
\cline { 2 - 3 } $\begin{array}{l}\text { Lipstik yang } \\
\text { terdaftar } \\
\begin{array}{l}\text { Lipstik yang tidak } \\
\text { terdaftar }\end{array}\end{array}$ & $15(100 \%)$ & $0(100 \%)$ \\
\hline
\end{tabular}

Berdasarkan Tabel 1 didapatkan bahwa baik lipstik yang terdaftar maupun yang tidak terdaftar semuanya (100\%) masih dalam batas aman yang telah ditetapkan oleh BPOM RI tahun 2011 tentang persyaratan cemaran mikroba dan logam berat dalam kosmetik yakni 3 ppm.

\section{Pembahasan}

Kadar Kadmium pada Lipstik

Berdasarkan hasil pemeriksaan kualitatif dan kuantitatif yang telah dilakukan kepada 28 sampel lipstik berwarna coklat gelap terdiri dari 15 sampel lipstik yang terdaftar dan 13 sampel lipstik yang tidak terdafatar di Pasar Raya Kota Padang, dan didapatkan pada semua sampel baik lipstik yang terdaftar dan tidak terdaftar di BPOM mengandung logam $\mathrm{Cd}$ dengan kisaran kandungan $\mathrm{Cd}$ yang ditemukan pada lipstik adalah 0,6708 - 1,4131 mg/kg. Berdasarkan peraturan BPOM RI nomor HK. 03.1.23.08.11.07517 tahun 2011 tentang persyaratan cemaran mikroba dan logam berat dalam kosmetika, dinyatakan bahwa batas cemaran $\mathrm{Cd}$ dalam kosmetika adalah $\leq 3 \mathrm{mg} / \mathrm{kg}$. Hasil uji kandungan logam berat $\mathrm{Cd}$ dengan menggunakan metode Spektofotometri Serapan Atom, tidak ada sampel yang melebihi batas yang ditetapkan oleh BPOM RI. ${ }^{11}$

Berdasarkan hasil pemeriksaan kuantitatif sampel dapat disimpulkan bahwa nilai kandungan $\mathrm{Cd}$ tertinggi pada lipstik yang terdaftar didapatkan pada sampel no. T12 (1,0953 ppm) dan pada lipstik yang tidak terdaftar pada sampel no. TT7 (1,4131 ppm). Secara keseluruhan kandungan tertinggi pada lipstik yang terdaftar dan tidak terdaftar yang telah diteliti berkisaran antara 0,6708-1,4131 ppm.

Penelitian sejalan dengan yang dilakukan oleh Ziaratti didapatkan kandungan Cd pada lipstik kisaran 1,1 ppm. ${ }^{13}$ Penelitian ini tidak sejalan dengan yang dilakukan oleh Yatimah di Jakarta, didapatkan 
kandungan Cd pada lipstik adalah 3,10236 ppm. ${ }^{14}$ Berdasarkan fenomena di lapangan diketahui bahwa BPOM telah gencar melakukan penyuluhan bahaya Cd di dalam kosmetik seperti lipstik sehingga didapatkan kadar $\mathrm{Cd}$ berada di bawah standar yang telah ditetapkan BPOM. ${ }^{15}$

Hal ini menunjukkan bahwa kandungan $\mathrm{Cd}$ pada lipstik yang terdaftar dan tidak terdaftar masih dalam batas normal dan memenuhi syarat untuk digunakan oleh masyarakat sesuai yang telah ditetapkan oleh BPOM. Kadar logam Cd walaupun dalam jumlah yang sangat kecil, namun tetap harus diwaspadai terutama pada pemakaian produk secara terus-menerus yang dapat menyebabkan terjadinya akumulasi logam berat. Akumulasi logam berat banyak terdapat pada organ hati, ginjal, dan alat pernafasan. Akumulasi logam berat di dalam tubuh manusia dalam jangka waktu yang lama dapat mengganggu sistem peredaran darah, urat saraf dan kerja ginjal. ${ }^{16}$

Logam Cd sangat berbahaya, hal itu disebabkan senyawa-senyawa $\mathrm{Cd}$ dapat memberikan efek racun terdapat tubuh. Keracunan Cd ini dapat menimbulkan gejala akut dan kronis. Gejala akutnya menyebabkan sesak dada, nafas pendek, sakit kepala dan menggigil. Gejala kronisnya akan menyebabkan kemampuan mencium bau menurun, berat badan menurun, gigi terasa ngilu, kanker payudara, dan penyakit kardiovaskular. Keracunan kronis ini tidak hanya menyerang sistem pernafasan tapi juga menyerang sistem pencernaan, ginjal, hati dan tulang. ${ }^{17}$

Absorpsi kadmium dalam tubuh masyarakat umum secara rata-rata $30 \mathrm{mg}$, yang didistribusikan dalam ginjal $33 \%$, hati $14 \%$, paru-paru $2 \%$ dan pankreas $0,3 \%$. Sisanya dieskresikan melalui saluran pencernaan. Pengaruh terhadap sistem pernafasan berupa edema paru-paru. ${ }^{18}$

Penelitian ini memiliki beberapa keterbatasan yaitu penelitian ini tidak melihat hubungan antara faktor-faktor yang mempengaruhi kontaminasi kadmium dengan kandungan kadmium pada sampel lipstik yang diteliti. Penelitian ini hanya menggunakan lipstik coklat gelap sebagai sampel penelitian yang dijual di Pasar Raya Kota Padang. Penelitian ini dilakukan di Pasar Raya Kota Padang yang merupakan pusat penjualan, sedangkan Kota Padang sendiri masih memiliki banyak lokasi penjualan lainnya.

\section{SIMPULAN}

Kesimpulan dari penelitian ini adalah seluruh sampel lipstik yang terdaftar dan tidak terdaftar di BPOM yang dijual di Pasar Raya Kota Padang, positif mengandung logam kadmium. Distribusi frekuensi kandungan kadmium pada lipstik yang diteliti ternyata dari semua lipstik baik yang terdaftar dan tidak terdaftar rata-rata kandungan kadmiumnya semua sampel berada dibawah batasan yang telah ditetapkan oleh BPOM.

\section{DAFTAR PUSTAKA}

1. Notoatmodjo S. Prinsip-prinsip dasar ilmu kesehatan masyarakat. Cet. Ke-2, Mei. Jakarta: Rineka Cipta; 2003. Hal.118.

2. Tranggono L. Buku pegangan ilmu pengetahuan kosmetik. Jakarta: PT. Gramedia Pustaka Utama. 2007;6.

3. Valda M, Citraningtyas FG. Analisis rhodamin b pada lipstik yang beredar di pasar kota manado. Jurnal ilmiah farmasi 2013; 2:61-66.

4. Barel, Andre O, Marc P, Howard I, Maibach. Cosmetic science and technology. 3rd edition). USA: Informa healthcare; 2009.

5. Mukaromah $\mathrm{AH}$, Maharani ET. Identifikasi zat warna rhodamin B pada lipstik berwarna merah. Pharmacon jurnal jlmiah farmasi 2008; 2(02):6166.

6. Departemen Kesehatan Republik Indonesia. Notifikasi Kosmetika. Direktorat Jendral Pengawasan Obat dan Makanan. 2010.

7. Agustina T. Kontaminasi logam berat pada makanan dan dampaknya pada kesehatan. Teknubuga. 2010; 2(2):53-65.

8. Widowati W, Sastiono A, Jusuf R. Efek toksik logam pencegahan dan penanggulangan pencemaran. Yogyakarta: Penerbit Andi; 2008. Hal.109-126.

9. Rowe I, Kibber AH, Talc, Sheskey PJ, Quin ME. Handbook of pharmaceutical excipient. USA: The pharmaceutical press; 2009.

10. Badan Pengawas Obat dan Makanan. Publik warning tentang kosmetika mengandung 
pewarna. Dilarang.infoPOM. 2012; 13(6).

Diunduh dari: jdih.pom.go.id.

11. Badan Pengawas Obat dan Makanan.

Persyaratan cemaran mikroba dan logam berat dalam kosmetik. Nomor HK.03.1.23.07.11.6662.

2011; 6. Diunduh dari: jdih.pomgo.id

12. Nourmoradi H, Foroghi M, Farhadkhani M, Vahid DM. Assessment of lead cadmium levels in frequently used cosmetic products in iran. Journal of environmental and public health 2013; $1-5$.

13. Ziaratti, Parisa I. Risk assessment of heavy metal contents (lead and cadmium) in lipstik in iran. IJCEA 2012; 3(6):450-452.

14. Yatimah YD. Analisis cemaran logam berat kadmium dan timbal pada beberapa lipstik yang beredar di daerah ciputat dengan menggunakan spektrofotometri serapan atom (SSA). Fakultas Kedokteran dan IImu Kesehatan. Skripsi. Jakarta: UIN Syarif Hidayatullah Jakarta; 2014

15. Badan Pengawasan Obat dan Makanan. Peraturan Pengawasan Obat dan Makanan Republik Indonesia. Jakarta: Badan Pengawasan Obat dan Makanan; 2014. Diunduh dari: jdih.pom.go.id.

16. Widaningrum $M$, Suismono. Bahaya kontaminasi logam berat dalam sayuran dan alternative pencegahan cemarannya. Buletin teknologi pascapanen pertanian 235. 2007; 23.

17. Sudarmaji J, Mukono, Corie IP. Toksikologi logam berat dan dampaknya terhadap kesehatan. Jurnal kesehatan lingkungan. 2006; 2(2):130-137

18. Darmono. Lingkungan hidup dan pencemaran. Hubungan dengan toksikokologi senyawa logam. Jakarta: Universitas Indonesia (UI) Press; 2001. Hal.10. 